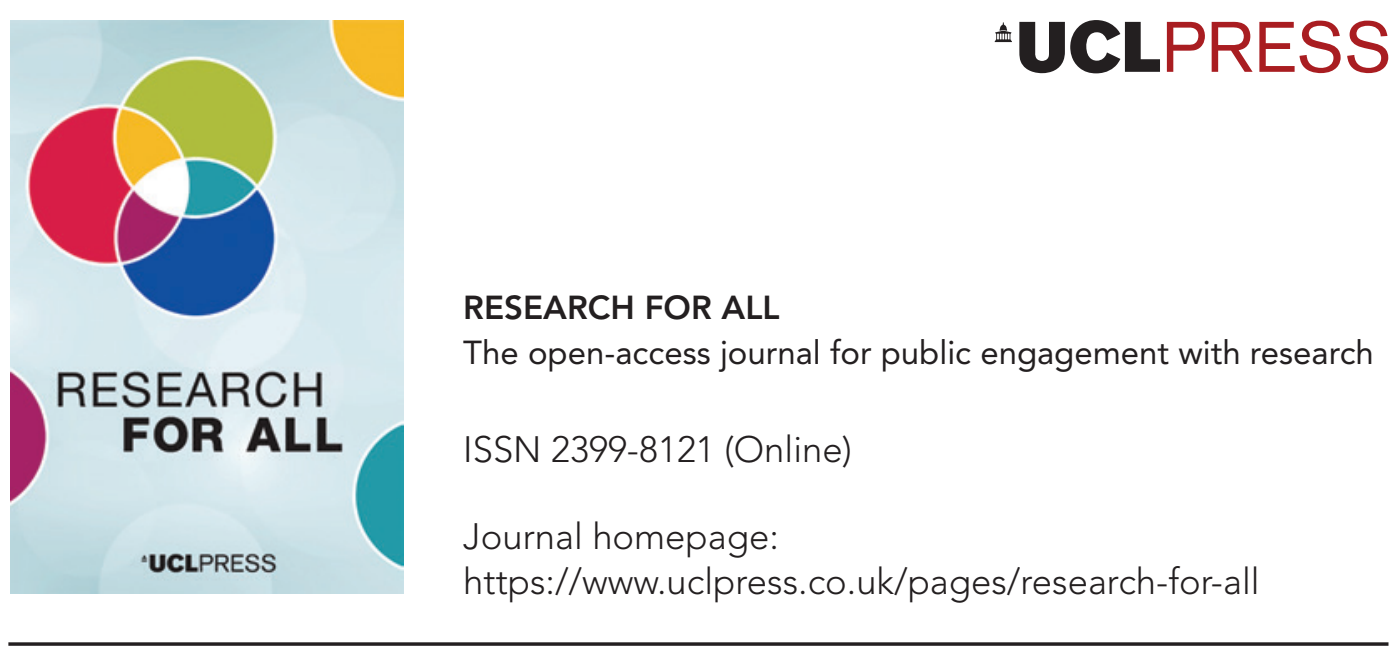

\title{
SCENE: A novel model for engaging underserved and under-represented audiences in informal science learning activities
}

\author{
Lindsay Keith (iD and Wyn Griffiths (D)
}

\section{How to cite this article}

Keith, L. and Griffiths, W. (2021) 'SCENE: A novel model for engaging underserved and under-represented audiences in informal science learning activities'. Research for All, 5 (2), 320-46. https://doi.org/10.14324/RFA.05.2.09

Submission date: 19 September 2020

Acceptance date: 23 May 2021

Publication date: 21 September 2021

\section{Peer review}

This article has been peer-reviewed through the journal's standard double-blind peer review, where both the reviewers and authors are anonymized during review.

\section{Copyright}

(C) 2021 Keith and Griffiths. This is an open-access article distributed under the terms of the Creative Commons Attribution Licence (CC BY) 4.0 https://creativecommons.org/licenses/ by/4.0/, which permits unrestricted use, distribution and reproduction in any medium, provided the original authors and source are credited.

\section{Open access}

Research for All is a peer-reviewed open-access journal. 


\title{
SCENE: A novel model for engaging underserved and under-represented audiences in informal science learning activities
}

\author{
Lindsay Keith* - University of Greenwich, UK \\ Wyn Griffiths* - Middlesex University, UK
}

\begin{abstract}
Inequitable access to science, technology, engineering, arts and mathematics (STEAM) has been explored by multiple studies which have shown that some publics are underserved by existing informal educational and cultural provision, and under-represented in related study choices and careers. Informal science learning (ISL) and public engagement with research activities (such as science festivals) tend to attract audiences which are largely white, middle class and already engaged with STEM (science, technology, engineering and mathematics). This article describes the development of an engagement approach and model through a story-based festival (SMASHfestUK) which was specifically designed to attract new and diverse audiences, including Black and mixed-heritage families, and families living with socio-economic disadvantage. The festival was delivered on five annual occasions, each co-designed with a wide selection of stakeholders, including audiences, researchers, performers, institutions and organizations, and considered as an iterative prototype.
\end{abstract}

Keywords: inclusion, engagement, festival, co-design

\section{Key messages}

- Engagement with STEM can be tailored to under-represented audiences by codesigning a festival format and content that resonates with those audiences.

- Enquiry-based learning with participants immersed in a meaningful story provides an opportunity for participants to experience STEM with agency.

- Success was built on the SCENE model (STEAM, community, enquiry, narrative, entertainment), co-designed hyperlocally, leading with free entertainment and an overarching narrative.

\section{Introduction}

This article reports the success of an engagement approach and model in building a new, inclusive science festival attracting up to four thousand local attendees in South East London. Visitors were new and diverse audiences: between 40 per cent and 50 per cent of adult attendees each year identified as Black, mixed heritage or another ethnic minority, rising to almost 70 per cent of attendees under 16 years old who reported their ethnicity (measured in 2016 only). More than 80 per cent of visitors lived in postcodes 
in lowest quintile areas according to the Index of Multiple Deprivation 2019 (MHCLG, 2019). Initial evaluation data suggest that a narrative-led approach may be effective in positively impacting attitudes towards STEM (science, technology, engineering and mathematics). Six principles derived from evidence-based literature encapsulated the approach to reaching new, diverse audiences, and these were synthesized into a novel model for inclusive engagement, SCENE (STEAM, community, enquiry, narrative, entertainment). This paper shows that the SCENE model for engagement was successful in attracting non-traditional and new audiences to events at the story-based festival, SMASHfestUK, and that engagement with STEM can be tailored to underrepresented audiences by co-designing festival formats and content that resonate with those audiences. Further, we show that enquiry-based learning with participants immersed in a meaningful story provides an opportunity for participants to experience STEM with agency.

This paper will discuss the co-design approach, and the role of place, representation, stories and narratives in the successful and inclusive engagement of visitors using SCENE in these events, and suggest ways in which informal science learning (ISL) can engage audiences inclusively through the adoption of SCENE principles.

\section{Rationale for the development of SMASHfestUK}

SMASHfestUK is a science and arts festival founded in 2014 to deliver public engagement activities in Lewisham, South East London. It was used to explore whether events specifically designed to engage under-represented audiences could succeed in doing so. Lewisham is ethnically diverse and highly deprived, with 30 per cent of children living with multiple indicators for poverty (MHCLG, 2015). Black and mixedheritage communities, as well as socio-economically disadvantaged communities, are under-represented in visitor demographics at ISL events and venues, making the area an appropriate site to explore inclusive engagement design.

There has been a drive internationally for greater uptake of STEM subjects and more diverse STEM workforces (Morgan et al., 2016). This is vital for developed economies, but also integral to social development, with STEM skills providing routes to improve quality of life (Nath and Border, 2013). Economically disadvantaged children are less likely to aspire to study STEM subjects or to work in STEM careers (Gutman and Akerman, 2008; Archer et al., 2015). Women are poorly represented in engineering, physics and chemistry, and Black British, Black-African and Black-Caribbean children are also under-represented in STEM post-16 and beyond (Macdonald, 2014; Mujtaba et al., 2010).

The reasons behind low uptake among certain demographic groups are complex. However, the concept of science capital has been useful in exploring barriers to engagement that can influence participation in STEM (Archer et al., 2013). Children from families with high science capital (typically middle class) are disproportionally more likely to pursue STEM post-16. Students with low science capital were more likely to be Black and working class, and less likely to choose STEM subjects (Archer et al., 2013). These groups were more likely to see science as 'not for me', and opinions about science as a career often demonstrated a narrow viewpoint (IET, 2008; TISME, 2013; Archer and Moote, 2016). Self-concept/image is integral to the decision-making process of young girls (Dewitt et al., 2014), and a lack of female STEM role models could contribute to this further (Chapman and Vivian, 2016). Archer et al. (2015: 943) suggest that one way to build science capital is by 'supporting students to perform a 
positive "science identity," to see themselves [as] (and to be recognized by others as being) a "science person"', along with the promotion of empowerment, democratic science teaching, learning and participation in informal learning contexts.

In parallel to this research on identity development, research exploring the role of storytelling in engagement suggests that it can have a 'strong and long-lasting' effect which can transform beliefs, attitudes and behaviours in real life (Green and Brock, 2000; Phillips and McQuarrie, 2010). Immersion within a story can result in a 'transformational experience' (van Laer et al., 2014), which occurs via a process known as 'narrative transportation' (Phillips and McQuarrie, 2010: 368), when individuals are emotionally engaged with a story to such an extent that it affects their subsequent attitudes. To date, there is little in the academic literature addressing the use of storytelling as a pedagogical method in ISL. We present here emerging findings following a multi-year programme of annual SMASHfestUK events exploring engagement approaches and, later, science identity.

SMASHfestUK was a story-led science and arts festival returning annually from 2015 to 2020 in South East London, and encompassing programmes of action research (Burns et al., 2011). The festivals aimed to explore ways of inclusively engaging local communities with STEM, first by attracting them to attend the ISL events, and thereafter by raising confidence in, and shifting attitudes towards, STEM learning by contextualizing knowledge within real-world contexts (stories) using hands-on, interactive and creative mediums to relay STEM concepts and theories. Development of the festival was guided by principles established through initial community co-design, and refined into a formal model through repeated iterations and co-design cycles. SMASHfestUK explored ways in which 'place' affects attendance demographics and engagement, and how co-design approaches can tailor content to under-represented communities. It explored how storytelling might enhance community relevance, and how enquiry-based learning through stories might enhance engagement and science identity.

A literature review was undertaken covering the evidence base for building science identity, ISL pedagogy, inclusive design practice, audience research, storytelling as a research tool and equitable access to public engagement, and it was used to support the establishing principles for SMASHfestUK, alongside co-design work (see Table 1).

Accessibility and the lowering of barriers, both real and perceived - geographical, financial, conceptual and representational - was key to the principles established (Burns et al., 2011; Froonjian and Garnett, 2013). A focus emerging from co-design workshops was the development of a dramatic, overarching but localized storyline, which integrated the festival programme into a coherent whole with meaning and resonance for visitors, and which was a way to explore self-identity.

The festival was delivered each year in the February half-term school holiday, across community venues in Deptford, in the Borough of Lewisham, South East London. Each festival was predicated on the story of an impending natural disaster which threatened the Deptford area. All activities and events at the festival related directly to the disaster storyline. Visitors were encouraged to become immersed in the story, embodied as actors with agency to affect the story, and the empowerment to change the outcome and 'save their world'. The 'disasters' were 'Asteroid' (2015), 'Solar Storm' (2016), 'Supervolcano' (2017) and 'Flood' (2018), and the festivals were semi-immersive in nature. Immersion within the storyline became an increasing focus, resulting in a fully immersive experience, 'Space Plague', in 2020, in which science identity was more fully explored. 


\begin{tabular}{|c|c|c|}
\hline Principle & Description & Evidence \\
\hline Use of STEAM & $\begin{array}{l}\text { STEAM (science, technology, } \\
\text { engineering, arts and mathematics): } \\
\text { an inclusive approach to engaging } \\
\text { audiences with STEM and the arts, } \\
\text { with recognition that this is vital for } \\
\text { meaningful learning, and creative } \\
\text { problem solving. }\end{array}$ & $\begin{array}{l}\text { (Land, 2013; Henriksen, } \\
\text { 2014) }\end{array}$ \\
\hline Hyperlocal & $\begin{array}{l}\text { An extension of the term 'hyperlocal' } \\
\text { beyond news media to mean } \\
\text { engagement in the heart of the } \\
\text { community. The festival would be co- } \\
\text { designed 'with the community, in the } \\
\text { community'. Venues would be local, } \\
\text { public and accessible, not museums } \\
\text { or university locations. }\end{array}$ & $\begin{array}{l}\text { (Foth et al., 2016; Cable } \\
\text { and Williams, 2014; Mytton } \\
\text { et al., 2014; Harden et al., } \\
\text { 2015) }\end{array}$ \\
\hline $\begin{array}{l}\text { Led by entertainment } \\
\text { (and not branded as a } \\
\text { 'science' event) }\end{array}$ & $\begin{array}{l}\text { To overcome barriers perceived by } \\
\text { those who think science is 'not for } \\
\text { me', it was not labelled as a 'science' } \\
\text { festival, but designed to appeal to } \\
\text { mainstream audiences. }\end{array}$ & $\begin{array}{l}\text { (Slater and Rouner, 2002; } \\
\text { Vorderer et al., 2004; Němec } \\
\text { and Trna, 2007; Archer and } \\
\text { Tomei, 2014) }\end{array}$ \\
\hline $\begin{array}{l}\text { Use of co-design } \\
\text { practices }\end{array}$ & $\begin{array}{l}\text { Working with stakeholders, including } \\
\text { audiences, researchers, STEM industry } \\
\text { and artists, empowers and engages } \\
\text { end users with the resulting product. }\end{array}$ & $\begin{array}{l}\text { (Sanders and Stappers, } \\
2008,2014 \text { ) }\end{array}$ \\
\hline $\begin{array}{l}\text { Use of an overarching } \\
\text { narrative }\end{array}$ & $\begin{array}{l}\text { Evidence from the use of stories to } \\
\text { engage and affect science identity } \\
\text { and attitudes in real life underpins the } \\
\text { narrative approach. }\end{array}$ & $\begin{array}{l}\text { (Gerrig, 1993; Phillips and } \\
\text { McQuarrie, 2010; Gallagher, } \\
\text { 2011; Dahlstrom, 2014; van } \\
\text { Laer et al., 2014; Schank } \\
\text { and Abelson, 2014) }\end{array}$ \\
\hline $\begin{array}{l}\text { Free at the point of } \\
\text { delivery }\end{array}$ & $\begin{array}{l}\text { Reducing barriers, including financial, } \\
\text { to underserved communities, } \\
\text { particularly when engaging people } \\
\text { living with socio-economic challenges. }\end{array}$ & $\begin{array}{l}\text { (Dawson, 2015; Grand et al., } \\
\text { 2015) }\end{array}$ \\
\hline
\end{tabular}

\section{Development of SCENE: An inclusive engagement model}

The development of SCENE (STEAM, community, entertainment, narrative, enquiry) drew on annual co-design cycles, each culminating in a festival followed by independent evaluation. The outcomes of each evaluation formed the basis of the co-design 'brief' for the next year. The first two festival cycles (2015 and 2016) applied the initial principles (Table 1), with SCENE (Figure 1) developing from this work and informing the festivals in 2017 and 2018.

STEAM: The contextual interconnection of all disciplines and knowledge areas in 'real life' was a critical founding philosophy of SMASHfestUK, as creative, interdisciplinary collaborations can underpin the development of compelling, meaningful experiences. The acronyms DSTEM (design, science, technology, engineering and mathematics/ medicine) and/or SHAPE (social sciences, humanities and the arts for people and the economy) apply equally.

Community: The SMASHfestUK principle of 'in the community, by the community, with the community' captures the SCENE intent of going to audiences and 
Figure 1: The SCENE model (credit: authors)

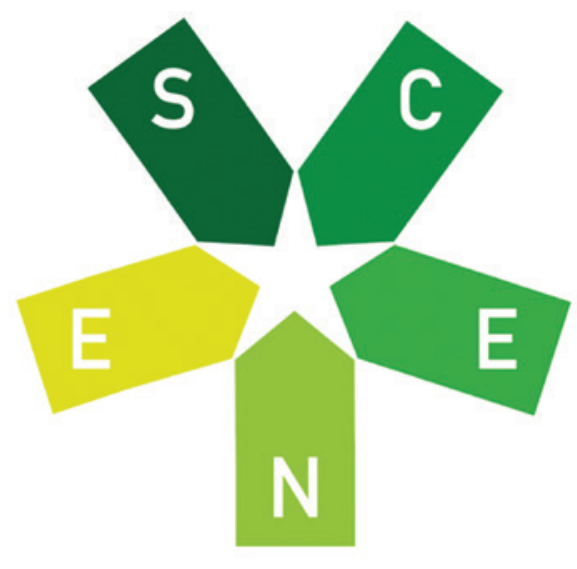

SCENE Model

Key:

$S$ - STEAM

C - Community

E - Entertainment

$\mathrm{N}$ - Narrative

E - Enquiry

participants to minimize barriers to access, and working with local people to engage as many as possible as active participants. Events are based physically at the heart of local communities, with clear representation of the community demographic reflected in the events and staffing.

Entertainment: All events were primarily 'entertainment first'; if an event would only be likely to attract an audience if the audience members were already engaged with STEM, the event would not be included in the programme. The events were not marketed as 'science festivals' (hence 'SMASHfestUK'), so as to reduce barriers to access for potential audiences who had been previously marginalized by ISL and/or who perceived science as 'not for me'.

Narrative: The use of an overarching storyline drove the event structure and approach, providing a coherent thematic framework for generative creative collaborations and visitor experiences. Stories also provided context and opportunity for 'narrative transportation' to potentially change attitudes in real life through immersion in stories.

Enquiry: Enquiry-based learning underpinned the intent to transform attendees from passive audience members to active participants, in an environment where 'problems drive the learning' (Deignan, 2009: 13). By creating a disaster-based narrative for SMASHfestUK events, the experiences are predicated on the need to problem solve, tasking visitors with the question, 'How can I help to save my world?'

\section{Methodology}

Each year, formative assessment contributed to further developments in both the design of the festival and the subsequent evaluation. This captured important learning, although the type and format of data varied over the years. Each annual cycle of development consisted of a series of co-design workshops with stakeholders, including community groups, specialists, students and local schools, resulting in a festival, including shaping its theme, structure, approach and content. These elements formed both the event itself and prototypes for the next cycle of development. Each festival was evaluated, providing the feedback to construct learnings for the co-design brief and briefings for the next cycle. 


\section{Co-design}

Co-design is a subset of co-creation which 'practiced at the early front end of the design development process can have an impact with positive, long-range consequences' (Sanders and Stappers, 2008: 9). It 'enables people to take ownership of their environments, services or products and, therefore, creates stronger and more meaningful connections among people and these creations' (Zamenopoulos and Alexiou, 2018: 24). For these reasons, co-design, which is integral to the professional practice of SMASHfestUK co-founder Wyn Griffiths, was fundamental in developing SMASHfestUK.

Each festival was considered as a live 'prototype', with post-event evaluation learnings incorporated into the next event co-design cycle. Co-design took place in community venues, schools and Middlesex University Design Studios. Each design cycle was framed by a generalized 'design brief' developed from the evaluations and research team observations, followed by tailored design briefs for developing specific insights/ideas from different participant groups. Groups included primary and secondary school students, mixed adult/child community groups, and specialist collaborations.

Tailored workshops were structured around ideation and prototyping tasks. Two or more researchers acted as facilitators. Each brief deployed 'design tools' developed at Middlesex University (Bardill et al., 2010; Griffiths et al., 2012) for ideation and experience prototyping. Workshops focused on what Sanders et al. (2010) describe as 'make tools' - large open-format paper rolls, A4 ideas templates and experience prototyping (Buchenau and Suri, 2000). Outcomes were usually paper-based insight/idea records, but they also included scripts, physical artefacts/installations, performances or films, depending upon the workshop and intent. Outcomes were sometimes festival events and experiences (delivered and facilitated with/by co-design stakeholders), or contributed towards events produced by the production team.

Adapted 'design sprints' (Banfield et al., 2015) were held with Middlesex University staff and students regularly throughout the cycles. Design sprints synthesized the workshop insights and idea outcomes into the development of both overview visions and specific event content for the festivals.

The top-level co-design process was a cycle: 'understand, create, implement, evaluate' (Figure 2). This was applied to the SCENE model (and/or the establishing principles) through the development process of each annual cycle (Figure 3).

\section{Evaluation methods}

An independent evaluation was carried out each year following the festival. The evaluators used mixed methodologies, collecting both quantitative and qualitative data. Initial evaluation in 2015 was limited by resources, with more in-depth and robust data collection with bigger sample sizes happening year on year, as resources allowed. Evaluation utilized front-end and summative methods that captured quantitative comparative data while allowing for qualitative reflection. The evaluations used researcher-administered questionnaires (using both closed and open-ended questions) for adults and children. The independent evaluation in 2015 was carried out by Bridget McKenzie of Flow UK (Flow UK, 2015). The 2016 independent evaluation was carried out by SAM-Culture, with help in measuring audience data and carrying out miniinterviews and assisting in questionnaire completion from the SMASHfestUK volunteer corps (Jarvis, 2016). The evaluation findings of 2015 and 2016 tracked attendance, and asked if attendees were from the locality and whether they had a positive experience. 
Figure 2: Top-level co-design process (credit: authors)

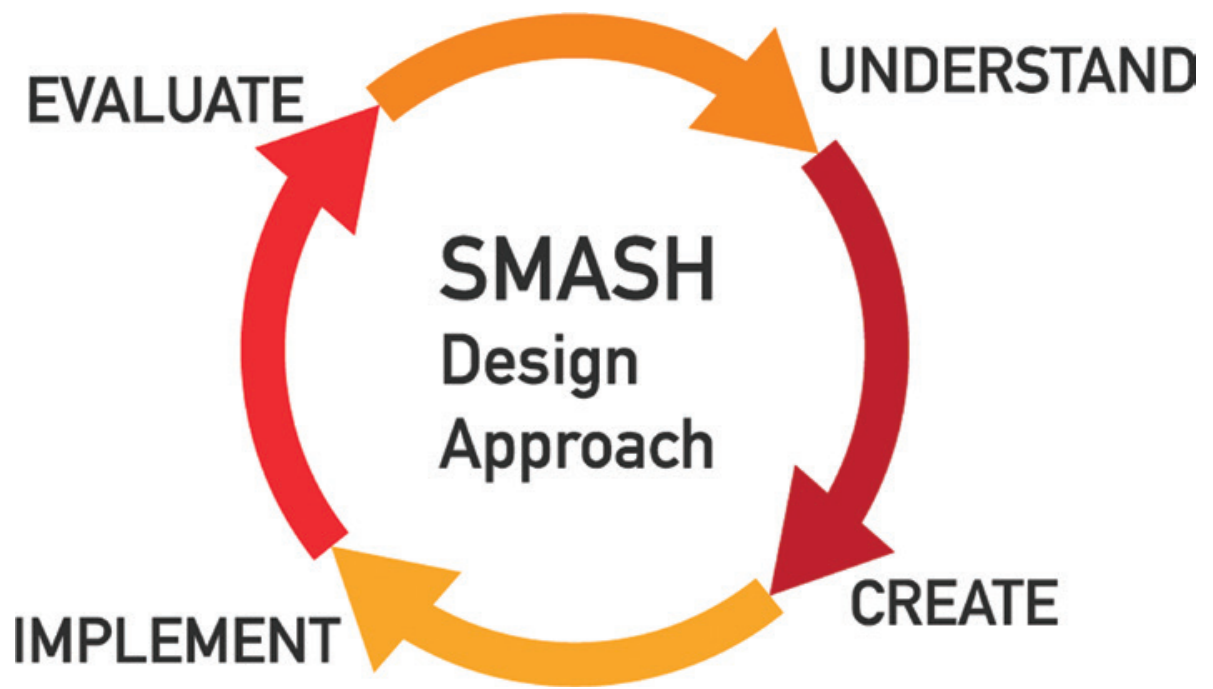

Figure 3: SCENE model incorporating co-design process (credit: authors)

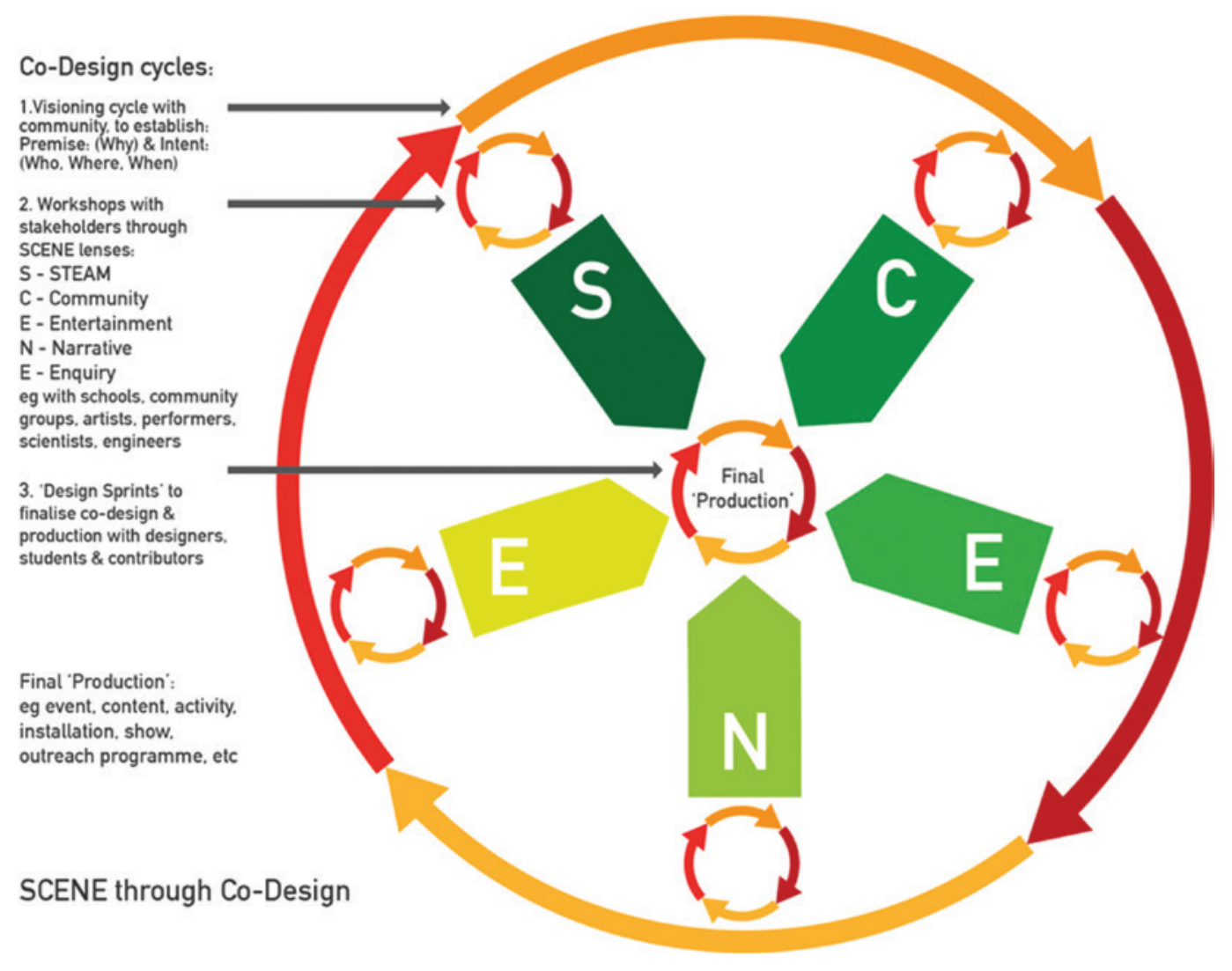

The 2017 and 2018 independent evaluations were carried out by Dr Natasha Simons, supported by SMASHfestUK volunteers (Simons, 2017, 2018). These evaluations examined in more depth the detail of the demographics of attendance, the engagement response and the effectiveness of the SCENE model in tailoring activities to underrepresented local audiences. 
Figure 4: Markers showing the locations of The Albany and the Deptford Lounge (illustration derived from Google Maps)

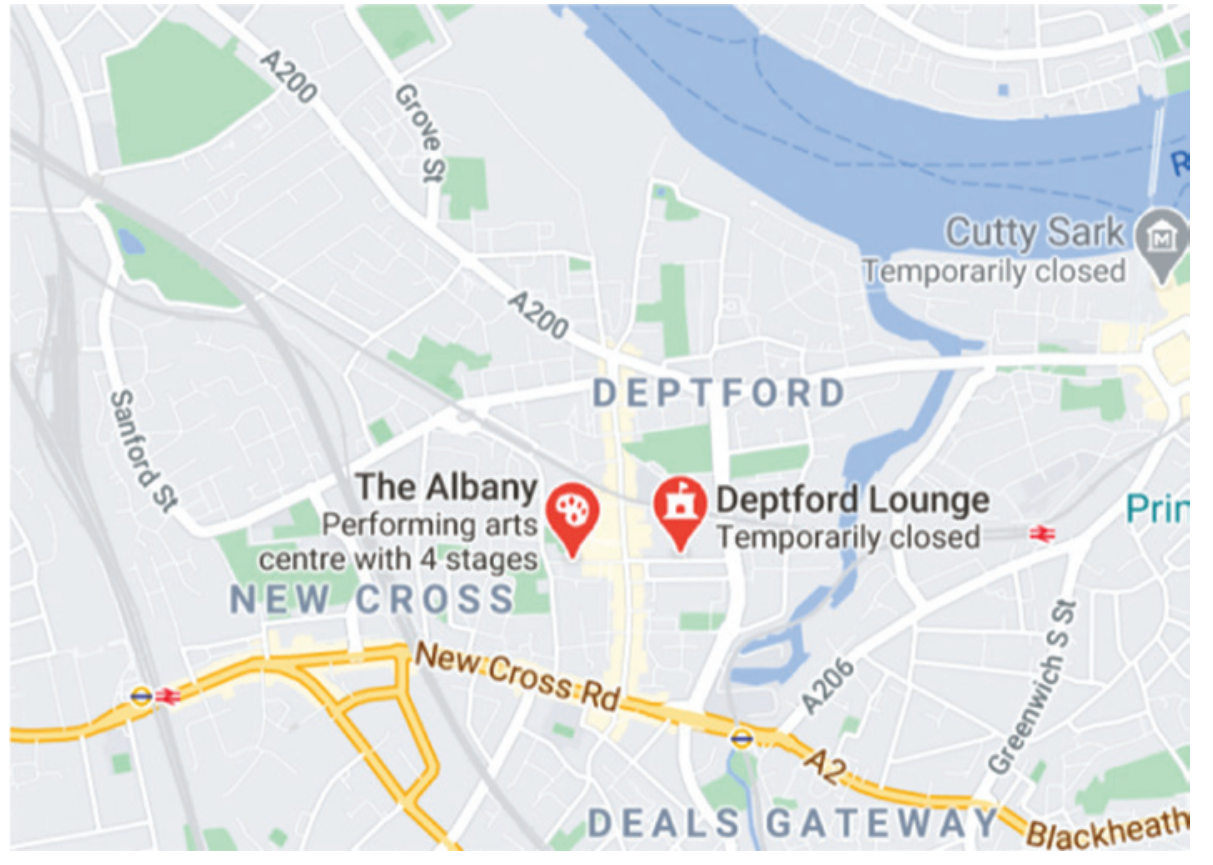

The festivals were mainly delivered across two venues, The Albany and the Deptford Lounge (Figure 4), and the exterior public spaces between the buildings, in the heart of Deptford, which comprises the Evelyn and New Cross wards in the north of the London Borough of Lewisham. The majority of Deptford and its environs (Figure 5) is in the lowest two deciles compared with the rest of the population of England, that is, in the 20 per cent of the population who live with the greatest poverty (Figure 6). The Albany is a modern open-plan theatre with a large public foyer and a café. SMASHfestUK hired all bookable spaces (café, garden, auditorium, two studios and three meeting rooms) to hold events (drop-in and ticketed) on two of the festival days. The Deptford Lounge is an open-plan community library which hosted drop-in activities over five days. The founding 'hyperlocal' focus was on attendance from SE postcodes surrounding the venues (Figure 7), with particular attention on SE8, the postcode of the venues, and SE14, the postcode outside SE8 that is closest to the venues.

\section{Results}

\section{Pre-'Asteroid' co-design}

Early co-design sessions with young people in South East London suggested that stories that incorporated concepts of excitement, adrenalin and fear were highly engaging for them. The co-design process resulted in a decision to build a narrative for each festival around a fictional (but theoretically possible) natural disaster. These were 'Asteroid', 'Solar Storm', 'Supervolcano' and 'Flood', in 2015, 2016, 2017 and 2018 respectively. Although these are potentially extinction-level events, in order to address the issue of 'otherness', and to ensure that attendees felt that these events were 'for me' rather than 'not for me', it was important to bring a local focus, so it was 
Figure 5: Deptford takes in Evelyn and New Cross wards in the north of the borough (source: Wikipedia Lewisham London UK labelled ward map 2002.svg licensed under CC BY-SA 3.0)

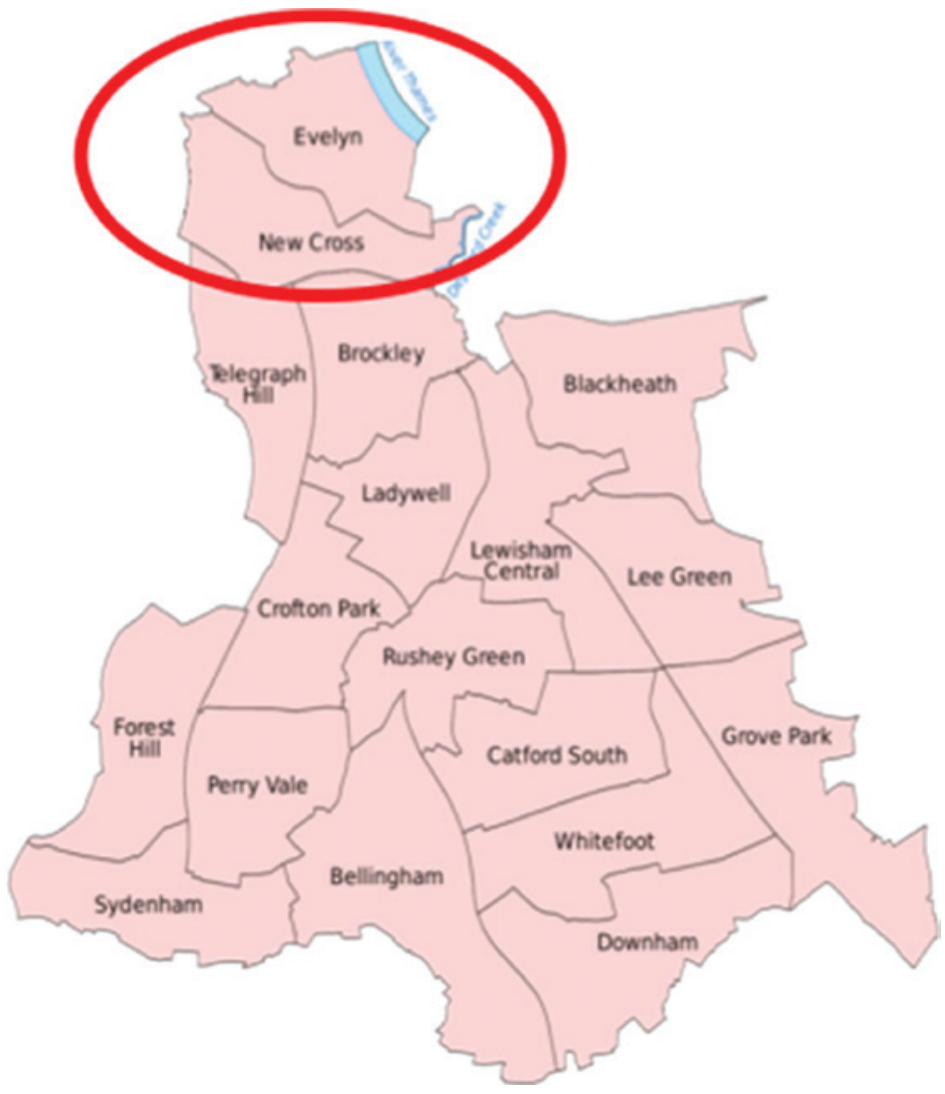

Figure 6: Data from Indices of Multiple Deprivation in England (MHCLG, 2019) mapped on to a map of the London Borough of Lewisham showing poverty in deciles, with darkest blue representing the greatest poverty (map created from IMD 2019 data by Alistair Rae, University of Sheffield (Rae, 2019))

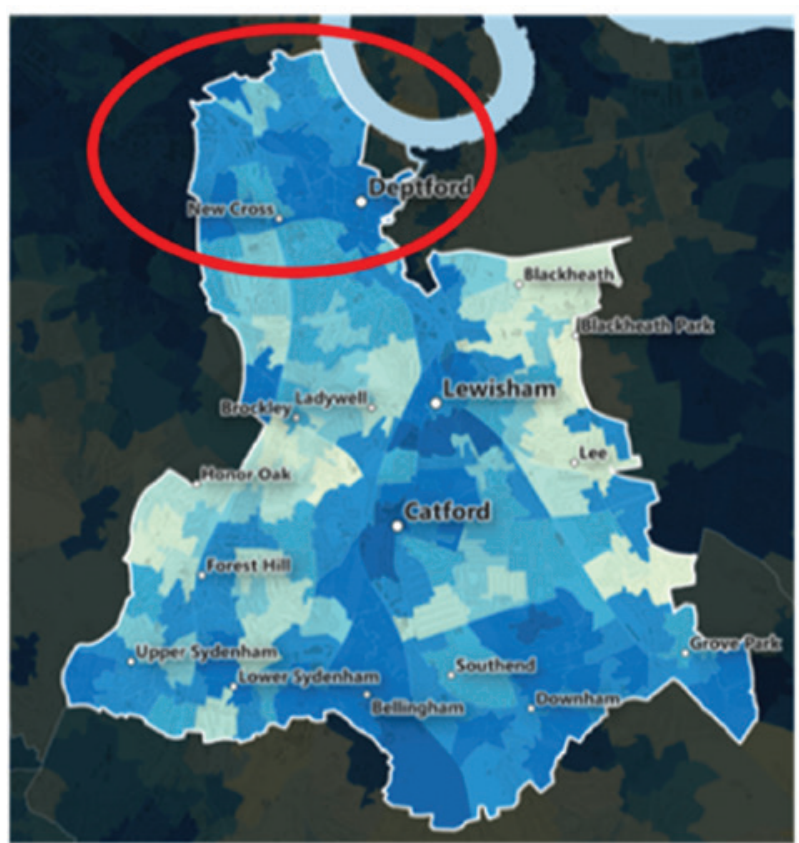

$9 \quad 0.0 \%$

$10 \quad \mathbf{0 . 0} \%$ 
Figure 7: Postcodes in Lewisham surrounding and including Deptford (SE8) (credit: Richardguk, contains Ordnance Survey and Royal Mail data $\odot$ Crown copyright and database right (2012), licence: CC BY-SA 3.0, https://en.wikipedia.org/wiki/File:SE_ postcode_area_map.svg)

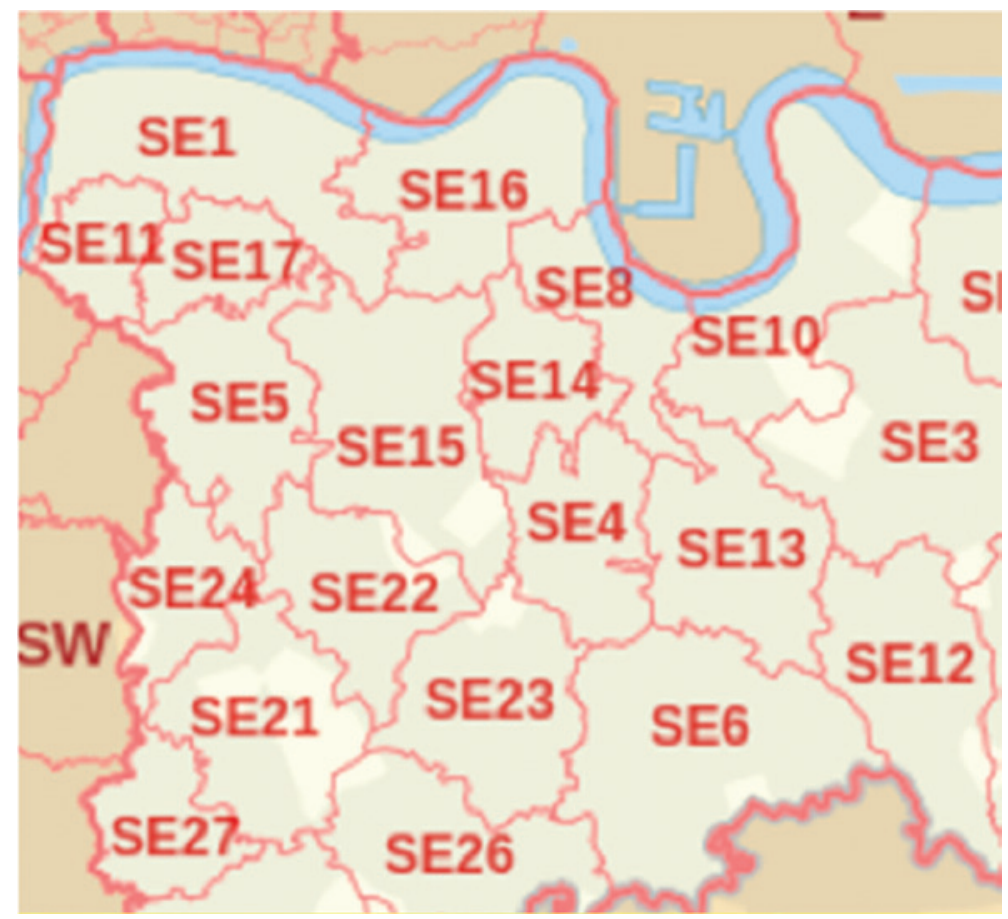

stressed that Lewisham was under threat, but that the wider world was also at risk. In framing the narrative this way, the audience was invited to help 'save (their) world', rebuild the world, or prepare to explore a space habitat.

In engaging with solving the problems, the audience would learn about the science of the natural phenomena, survival physiology, basic engineering concepts for construction and mechanics, space science and related disciplines. Visitors would be encouraged to see themselves as future scientists or engineers, and imagine, through playing and doing, the roles that they might be able to play in saving humankind in the future.

\section{Attendance, motivation and demographics (2015-2018)}

Each year, a formative assessment contributed to further developments in both the design of the festival and subsequent evaluation. This captured important learning, although the type and format of data varied over the years. We summarize the data gathered from 2015 to 2018 on attendance, motivation for attendance and attendance demographics in Table 2. The evolving evaluation format resulted in variation in the data gathered, so we have distilled the data to highlight key commonalities and differences over the years. Ethnicity categories for 2016 were based broadly on Lewisham Census 2011 categories, with increasing granularity included in 2017 and 2018, in order to study whether the visitor groups were broadly representative of the area. A significant omission in the census and in our evaluation was identified through visitor feedback in later events (2020 onwards) and the category of 'Black British' was added. 


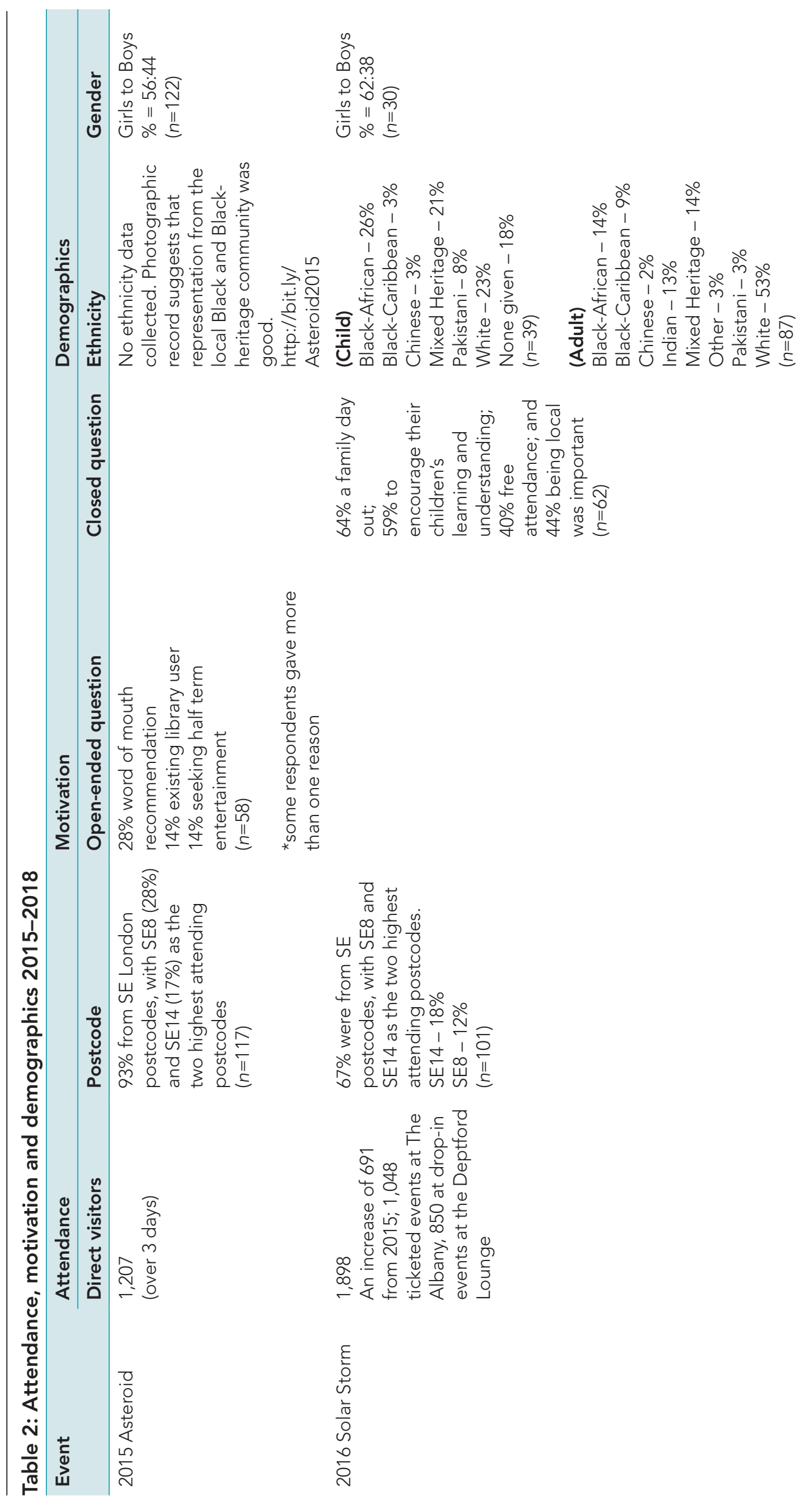




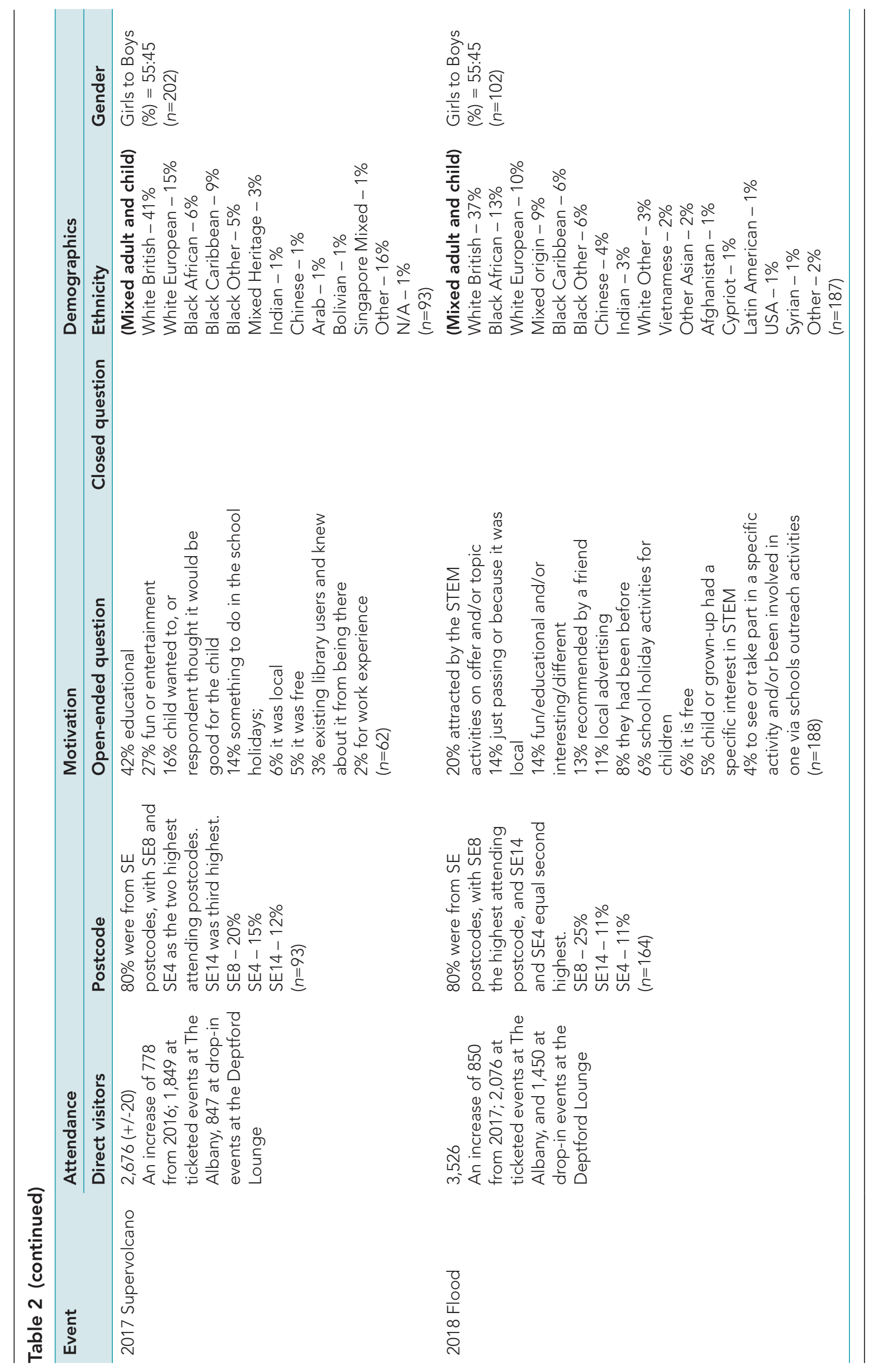




\section{5: "Asteroid" \\ Description}

SMASHfestUK 2015 was themed around the story of a large asteroid on collision course for Earth. All facilitators/performers were briefed to engage visitors with their activities or performances within the context of this story, and within the wider context of space science and survival physiology, should the asteroid impact necessitate the evacuation of Earth and a future life in space. Examples of events and activities included 'Survival Supermarket Sweep' (a gamified interactive installation of an 'apocalyptic' corner shop which taught survival physiology and nutrition), 'Godzilla in Deptford' (an interactive art installation exploring gentrification and destruction of habitats by external forces) and 'Live Emergency Room' (live simulation of emergency surgery on trauma injuries caused by meteorite fragments).

\section{Results 2015}

Data in 2015 showed that the majority of visitors came from the local community, with the greatest representation from SE8 (see Table 2), which encompasses the festival venues and is one of the most deprived wards in Lewisham, with 1,645 children living in poverty.

This indicated that the principle of being 'hyperlocal' - basing activity within the targeted community in accessible locations - was successful in attracting an audience drawn from the local community.

No data on ethnicity were collected in 2015. However, the photographic record suggests that representation from the local Black and Black-heritage community was good (Griffiths, 2015). It was decided to assess ethnicity data in more detail the following year to confirm whether attendance was representative of the postcodes captured and the local demographic.

\section{Reflections and learnings 2015}

\section{New audiences}

The event helped reach new audiences, notably drawing audiences to the theatre venue, which they were less likely to have entered before, despite its proximity (within a hundred metres) to the library, with the evaluator concluding:

Part of the festival was in Deptford Lounge, where regular users of the library were drawn to the other events in [T] he Albany. Many of these had not heard of or visited [T]he Albany, despite being very local. One volunteer reported that visitors, once engaged, would visit multiple events within the festival, and that for some this was a new experience. (Flow UK, 2015: 3)

\section{Engagement}

One key finding from the evaluation was that the overarching story had worked well as a hook for engagement, with families buying into the fictional story, which drove their interaction with events at the festival: 'The concept ... as a unifying theme behind all the different activities and performances was very clever and effective. Children played along with the "let's pretend" of it, asking with excitement if the [asteroid] strike was really going to happen'. (Flow UK, 2015: 2) 


\section{Story and immersion}

Narrative/immersive, entertainment-led and character-led shows were most popular (data not shown). The immersive gamified experience 'Survival Supermarket Sweep' was rated as the favourite event (23 per cent), followed by 'Dr De'ath' - a character-led performance about medieval medicine (19 per cent). Evaluators noted:

The Supermarket Sweep activity was mentioned most often as the most enjoyable activity. It was also the most successful as a learning experience, because children were returning to do it again and again. They were trying to get a better score each time, learning by trial and error what food stocks would be the most nutritious and sensible in a disaster. This is an excellent example of game-based learning, where you can progress in steps and improve through practice. (Flow UK, 2015: 3)

This gave insights for the design and production team to take forward and incorporate into the next cycle of co-design for future festivals.

\section{Key learnings for 2016 briefing}

1. The 'hyperlocal' approach appeared successful, so the team should expand the schools programme to connect with more local young people.

2. The use of STEAM and an 'entertainment first' approach seemed successful, so the team should develop more SMASHfestUK co-productions incorporating these principles.

3. The overarching narrative was engaging, so the team should develop more character-led, community-based theatre productions.

\section{6: 'Solar Storm"}

\section{Description}

The 2016 storyline was of a powerful coronal mass ejection from the sun ('Solar Storm') that could severely disrupt electrical and electronic signals and infrastructure. SMASHfestUK productions built on the success and focus of 'Survival Supermarket Sweep'. In partnership with Middlesex University, a 'f100 DIY Planetarium' was installed in the library venue and hosted regular planetarium shows to become 'London's second planetarium'. A fully immersive 'Survival Village' was created, where visitors worked with scientists and engineers to build vital technologies for survival (such as shelter, heating and water supply). To develop the narrative, a new contemporary play was commissioned, Cosmic Jives, featuring a young Black female protagonist (and aspiring astronomer) from Deptford whose world is threatened by a massive solar storm. The compelling narrative touched on the 'Matilda effect' (the structural bias against female scientists in history), as well as referencing well-known places and landmarks in order to engage local audiences (Rossiter, 1993). Members of local youth drama groups were engaged, and performed as a contemporary 'Greek chorus' in each performance.

\section{Results 2016}

Postcode data again showed that most attendees were from SE postcodes, but SE14 overtook SE8 as the most represented postcode (see Table 2). The festival attracted an ethnic breakdown of visitors that broadly represented the local SE8 community, 
at both adult and child level, with Black-African, Black-Caribbean and Mixed-Heritage comprising more than half of young visitors (see Table 2).

\section{Reflections and learnings 2016}

\section{New audiences}

The 2016 event successfully attracted new audiences, with 75 per cent of respondents reporting that they had never attended a similar event before, suggesting that the majority of the audience may not regularly seek out such ISL experiences or events (Jarvis, 2016). Marketing in 2016 had involved wider coverage and listings in popular London-wide publications, such as Time Out. While this may have contributed to increasing the audience overall, this was at the expense of local representation, with SE14 overtaking SE8 (the target audience of Deptford, and the location of the festival) as the most well-represented postcode among visitors. Although SE14 has some demographic overlap with SE8, it also covers a more affluent area, with less diversity and fewer socio-economic challenges than SE8. The decision was made that the following year, marketing resources would focus on local channels in order to bolster the SE8 audience.

By the completion of the 2016 evaluation, some elements were beginning to bring clarity to the SCENE approach. It was clear that while being free and local was not necessarily the primary reason that people attended, these were important factors for a considerable proportion of the attendees. This was borne out in feedback from audience members. When asked an open-ended question, 'What has been the best thing about SMASHfestUK for you?', one responded: 'Lots of adults and young people coming together to have fun and learn ... and it's free!' Another said (in response to the same question) that it provided 'affordable activities that have thrilled my daughter throughout the holidays', suggesting that she had visited multiple times, while another said, 'The opportunity for a fun day with the children watching them learning and enjoying themselves (whilst learning myself!)' (Jarvis, 2016: 7).

\section{Engagement}

The evaluation confirmed that the audience had a positive experience, with 96 per cent agreeing that something appealed to them at the festival, and 99 per cent agreeing that it was a good way to find out about science (Jarvis, 2016: 8). Although only 21 per cent of attendees gave 'learning' as a reason for attending the event, 95 per cent agreed that they had learned something new (Jarvis, 2016: 8). This suggests that leading with entertainment was important, as the majority of parents were not looking for an educational event, but enjoyed it and learned new things once there. Audiences were also supportive of the narrative approach. When asked, 'What has been the best thing about SMASHfestUK for you?', one responded, 'Diverse, interesting and fun activities but all relevant to the theme' (Jarvis, 2016: 8), while another commented on their favourite activity (Cosmic Jives), saying that it had a: 'Clear storyline. Strong acting. Good message.' Attendees also reinforced that the event was particularly good for girls, with one saying the best thing about SMASHfestUK was 'the girls and science', and another saying it was 'inspiring my daughter that science is fun, is artistic and is for girls' (Jarvis, 2016: 12). Another adult visitor (reporting in a post-event interview) expanded on this theme, saying: 'It's also good to see girls taking an interest in subjects they thought were boring and to meet scientists and university students - and to see the lightbulb go on' (Jarvis, 2016: 17). 


\section{Story and immersion}

Children enjoyed the hands-on and interactive activities the most, which were ranked as favourites by 60 per cent of attendees, despite making up only 48 per cent of the scheduled events, suggesting the effectiveness of the enquiry-based learning approach (Jarvis, 2016).

In post-event evaluation interviews, one 16-year-old contributor reflected on the experience, and highlighted many aspects of the establishing principles of SCENE by saying:

It's great that there are events like this that bring a chance to people who wouldn't usually engage. Young people liked how the Festival was on the High Street, they don't see these sorts of things in the rigid environment of school and they can't explore these sorts of ideas. I enjoyed explaining ideas to children and parents and I learned a lot of new things that you don't usually put together in the conventional sense. The arts make it all more creative and putting things together in different ways reveals the overlaps. For people who don't engage with science it hooks them in and makes them want to find out more. (Jarvis, 2016: 16)

The insights reinforced the basic principles of engagement followed from 2015 into 2016, and the independent evaluation gave key learnings going forward into 2017, with Jarvis (2016: 21) reporting: "What if...?" [is a] compelling narrative that forms the basis for all events and activities [and] presents audiences with a coherent story [that] works well in capturing their attention and imagination and opening up dialogue and engagement in complex issues.' The report also suggested that the festival was already 'seeing a level of repeat attendance, awareness and goodwill, and these are strengths that can be built upon', and that interaction within the immersive experiences was important:

SMASHfestUK provides opportunities for young people to meet people who have a wide spectrum of interesting careers. The opportunity to meet and talk to artists and scientists alerts them to potential new directions that their futures could take. This is a valuable aspect of SMASHfestUK that could be developed. (Jarvis, 2016: 21)

\section{Key learnings for 2017 briefing}

1. Focus communication and marketing resources through local schools and local channels.

2. Create more opportunities to meet positive role models.

3. Widen and deepen the immersive and narrative aspects of the festival.

\section{7: "Supervolcano" \\ Description}

SMASHfestUK 2017 took place in the two usual venues (theatre and library) over two days during the school half-term holiday in February, with drop-in activities throughout the whole week. An extensive schools enrichment programme was undertaken, working with 12 local primary schools who contributed to building a five-metre high model of a cryovolcano which 'erupted' as the centrepiece of the festival, broadcast 
online by Guinness World Records. The 'Survival Village' returned, engaging families with survival engineering and construction. A new play entitled Rupture explored the devastating effects on a young Black woman of the volcanic eruption in the Caribbean island of Montserrat. She is evacuated and later finds herself as a resident of Deptford, reflecting on her experience.

\section{Results 2017}

Postcode data again showed that most attendees were from SE postcodes, with SE8 returning to be the most represented postcode (see Table 2). Audiences continued to grow, while retaining an attendance broadly representative of the area (see Table 2).

\section{Reflections and learnings 2017}

\section{New audiences}

Asked whether they had been to a similar event before, 19 per cent of visitors had previously attended a similar event, 17 per cent had been to a previous SMASHfestUK event, and examples of similar activities or events attended before included the Science Museum, Underbelly at the South Bank and various other UK science festivals. For 71 per cent of the audience, however, SMASHfestUK represented a unique experience, suggesting that it is successful in reaching new audiences and people who have not previously engaged with ISL.

Qualitative responses supported the assertion that travel and accessibility can make a difference to whether people attend. When asked the open-ended question, 'Why is it important that it is held in Deptford?', one respondent replied, 'Don't need to travel', and another said that it was 'easier to get to'. Another said: 'so much easier having it local. It's so tiring going up to London, paying and going on the tube'. Others remarked that centring the activities in the heart of the community, especially a community facing socio-economic challenges, is important, saying that 'This is not a rich area, events are free, so can engage audiences that do not normally come', with another saying, 'to bring the community together, allowing less loitering and gang activity'. Another responded: '[lt's a] deprived area. So good to provide activities here for the local community'. There was also a recognition that this type of activity/event is not often found in these communities, with another respondent noting that the best thing about the festival is 'to offer access to facilities not normally available to children and adults' (dataset for Simons, 2017).

Others noted that specific costs are unachievable for them. A woman who runs a children's care facility remarked: 'There are not many opportunities in Deptford for kids (that are affordable) ... f2 is [our] max[imum] limit, and transport can push costs up' (Simons, 2017: 35). People from outside the locale still recognized the importance of having local engagement, saying that the best thing about SMASHfestUK is 'engaging with local population rather than being held in [central] London - a different audience', and another remarking, 'I think there are a lot of clever children in Deptford - so great for people who can't access things like this' (dataset for Simons, 2017). For one parent, having a local, accessible activity for children was important because 'It gets people off the streets', concluding that it 'gives people like me somewhere to go with the children, otherwise l'd be drinking on the streets' (dataset for Simons, 2017).

With better resourced evaluations and data collection, a richer picture began to emerge of why a model such as SCENE, and a hyperlocal approach, can be deeply important for communities living with socio-economic disadvantages. Not only did the approach appear to be building capacity to engage both new and returning audiences, 
but the audiences also broadly reflected the demographics of the local population, with a good representation of ethnically and socio-economically diverse visitors. This is in line with the findings of the ASPIRES study, which reported that for many people facing barriers to access, it is poverty of opportunity, not poverty of ambition, that prevents them from engaging with STEM ISL (Archer et al., 2013).

\section{Engagement}

When asked closed questions about their engagement with the event content, respondents overwhelmingly agreed that they, as adults, and their children had learned new things, with 85 per cent strongly agreeing or agreeing that their children had learned something new, and 88 per cent of the adult respondents either strongly agreeing or agreeing that they had learned something new; 90 per cent of the respondents strongly agreed or agreed that SMASHFestUK helped to bridge the gap between the arts and science, and 94 per cent of the respondents strongly agreed or agreed that the event helped to show how science can be useful or relevant to everyday life (Figure 8).

Overall, 96 per cent rated SMASHfestUK 2017 'Supervolcano' as excellent (71 per cent) or good (26 per cent). The children's favourite overall activity was the play Rupture (Simons, 2017).

\section{Story and immersion}

Again, the narrative had been an important part of engagement, allowing for connected learning experiences across a range of STEM disciplines and activity types. When asked 'What could SMASHfestUK change next year?', 26 per cent of (adult) responders said, 'Nothing', and of those responding to the closed questions 'How important is it that SMASHfestUK provides opportunities to engage with science?' and 'How important is it that SMASHfestUK provides opportunities to engage with the arts?', 90 per cent in both cases agreed or strongly agreed that it was important (data not shown). Among respondents to the questionnaire for children and young people,

Figure 8: Indicators of engagement 2017 (closed ended, n=58) (Simons, 2017)

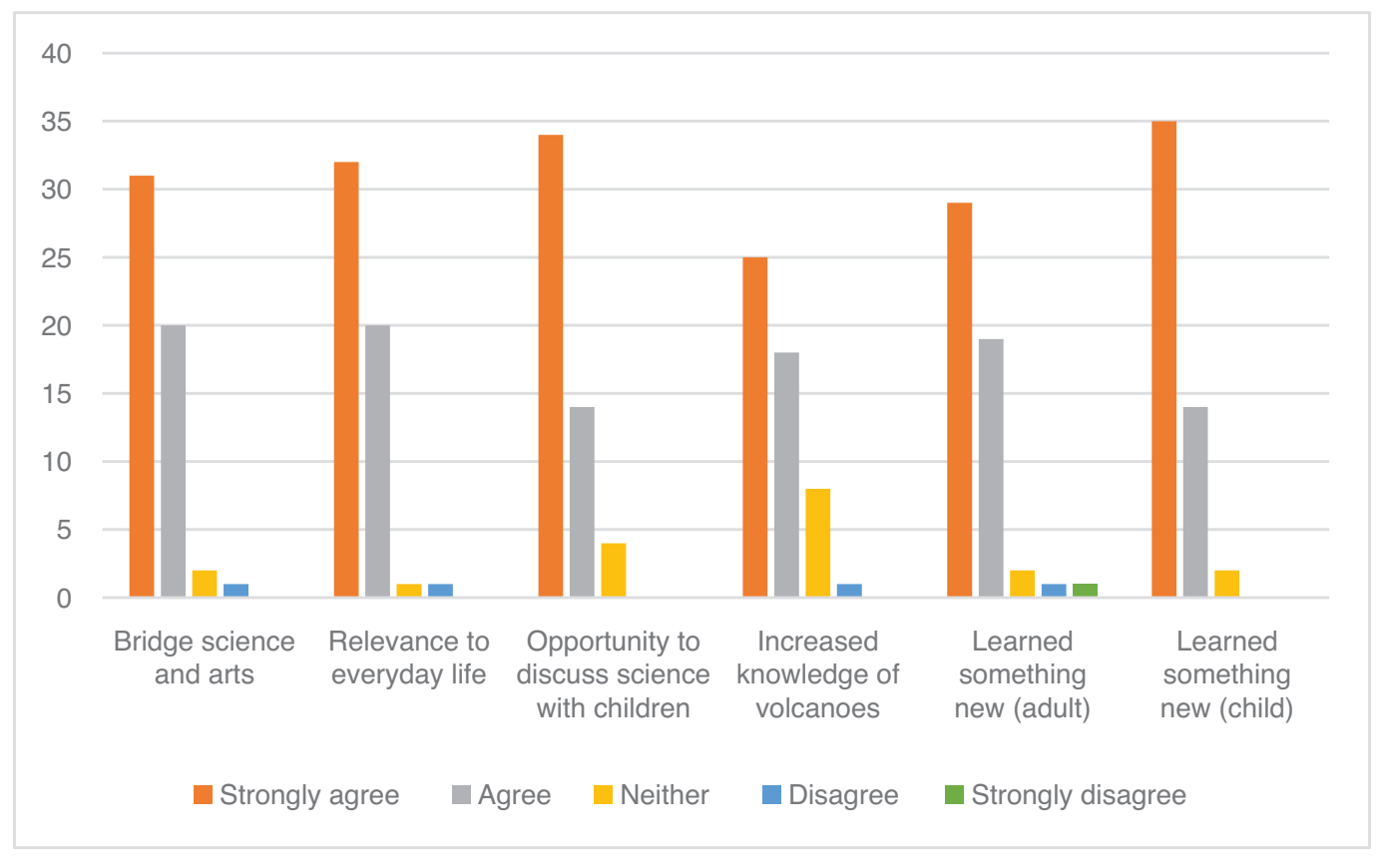


the favourite activity was the play Rupture (14 per cent), followed by the Guinness World Records cryovolcano explosion, making a volcano (science/craft) and 'Survival Supermarket Sweep' (which had been delivered again after success in 2015), all with 11 per cent, and an 'ID card activity', placing visitors within the story and providing careers inspiration, with 9 per cent (Simons, 2017). This attraction to the narrative themes was supportive of the effectiveness of 'story' in engaging young people. The effectiveness of the story was not lost on adults either, however. One adult interviewee reported her engagement with an installation about Mount Soufrière, a volcano that erupted in the Caribbean in 1979, sparking a mass evacuation. The installation was a volcano 'ziggurat', within which the voices of local children read aloud the historical testimonials of survivors, played over a soundtrack of pyroclastic activity. The interviewee said: 'I did the immersive Montserrat volcano experience - listening to the kids reveal their volcano stories made me ponder and imagine that I was there. I learned about volcanoes on the Moon, Mars and Venus.' Such statements suggest that while children may be drawn in by the excitement and thrills provided by immersion, for adults, the engagement through narrative can be deep and meditative.

Festival experience also resulted in positive science learning outcomes. Of adult respondents, 65 per cent reported new learning, with 36 per cent giving specific examples of what they had learned, and 77 per cent agreeing or strongly agreeing that they had learned about volcanoes (Simons, 2017). An interesting observation by the evaluators was that respondents in the library venue were less confident about their learning than those in the theatre venue. Library visitors were also more likely to be drawn from the immediately adjacent postcode (SE8) than visitors to the theatre venue (Simons, 2017). This reduced confidence was observational, but it was reflected in their comments. On reflection, it was clear that activities offered in the library skewed towards arts, crafts and younger children, with fewer interactive science or immersive activities. It was decided that in 2018, the team would redress this balance of activities, and make further efforts to draw library users to the theatre venue.

\section{Key learnings for 2018 briefing}

1. Increase the variety of immersive, interactive and strongly science-based activities in the library venue.

2. Deepen the immersion and 'localization' aspects of the storyline further.

3. Increase and improve the link between activities at the festival and future careers.

\section{8: "Flood"}

\section{Description}

The narrative for the 2018 festival further enhanced the local flavour of the story to anchor it in the community. 'Flood' was about Deptford being in the path of a tsunami that threatens to overwhelm the Thames Flood Barrier, returning SE8 to a floodplain. Visitors were invited to explore how tropical diseases such as malaria might come to the UK as climate change warms the Earth. Visitors were also encouraged to explore alternatives to terrestrial life in an immersive 'Living in Space' experience, in which visitors were 'space cadets' who 'graduated' if they interacted with all activities. Separate interactive activities (epidemiology, microbiology and forensic water analysis) were linked by a story in which visitors were tasked with finding the cause of an outbreak of 
a disease in Deptford. An immersive theatre performance, The Mysterious Case of the Flood in the Night-Time, positioned the audience as a jury in a coroner's court during an inquest to determine the cause of death of a man who had lived on a canal boat in Deptford Creek. This involved forensic science, critical thinking and determining the cause of death (yellow fever, following a mosquito bite), with learning outcomes about climate change and disease. Another activity, 'Survive the Swamp', created a gamified immersive experience where visitors had to problem-solve to traverse a post-'Flood' polluted swamp, avoiding deadly obstacles and gathering survival resources on the way.

\section{Results 2018}

Postcode data showed that most attendees were from SE postcodes, with SE8 continuing as the most represented postcode (Table 2). Audiences continued to grow, while retaining an attendance broadly representative of the area (Table 2).

\section{Reflections and learnings 2018}

\section{New audiences}

SMASHfestUK in 2018 again played mostly to new audiences who had not attended a previous SMASHfestUK event. Of attendees who responded to the survey $(n=188)$, almost 70 per cent had never been to a previous event, with 25 per cent having attended one or more SMASHfestUK events in 2015, 2016 or 2017. Asked how often they sought out informal science learning activities, 45 per cent answered never, or rarely (1-2 times per year); however, 52 per cent were regular attendees at ISL events or activities (3 to $6+$ activities annually).

Asked the reasons for their attendance in a closed question, visitors reported that they were attracted by the STEM activities (20 per cent), with it being 'fun or educational' (14 per cent), although it is also interesting to note that, now in its fourth annual iteration, more and more attendees were coming following advertising (11 per cent) or recommendation (13 per cent). While this speaks to the popularity of the events, it is perhaps unsurprising that this might create a feedback loop, where more people were returning who were already engaged with, or interested in, science, or possibly had become so due to previous SMASHfestUK attendance. There was still a small percentage (6 per cent) who said that the event being free was their main reason for coming, with 14 per cent attending because it was local and/or they were passing by (Simons, 2018). Comments from adult attendees supported the importance of this in-community approach. One parent reported that their primary concern was 'Location - so pleased that this standard (excellent) of organization - the event came to Deptford! - didn't need to go to the Science Museum' (dataset for Simons, 2018).

Despite this, given the open-ended option to add 'any other comments' about the event, out of 33 responses, there were 25 mentions of the event being local and/or free, suggesting that this continued to appeal to, and was important to, attendees who live in the area. One commented that being free helped to make access equitable, saying: 'We thought that it was great thank you! Especially all the helpers they were great. If an event is free it is not being prohibitive everyone welcome - that's a brilliant sentiment.' The comments offered further insights into attracting new audiences, with one visitor saying that SMASHfestUK is 'close to my house and it is free and there is lots to do' (Simons, 2018: 32). 
Two interviewees provided particular insights regarding the location of the festival in the heart of South East London: 'I grew up here, I now live in Bromley and have travelled back for this, nothing like this happens where I live and there is no real sense of community. But it is hard, you know, to engage people from deprived areas.' A great-grandmother who visited with her two great-grandsons talked about the value of SMASHfestUK being located in a place where the boys feel comfortable, as this impacts on their engagement and learning:

... they are still here, they have made rockets and they loved that. At first they were a bit bored as they didn't know what to do, but the organizers here are great and really engage the kids in the activities. The boys have really enjoyed it and got a lot out of it. Being in the community makes it feel comfortable for them - they feel that it is for them too. (Simons, 2018: 33)

\section{Engagement}

Visitors were asked what they liked about the event, and what they felt they had got out of visiting. Most people who answered these questions strongly agreed or agreed (96 per cent) that their children had learned new things; 80 per cent of adults felt that their own knowledge had increased, and 86 per cent agreed that it enabled them to discuss science with their children; 90 per cent agreed that it helped to show how science relates to everyday life, and 93 per cent agreed that it helped bridge the science and the arts (Figure 9).

Overall, 96 per cent of respondents rated the experience as 'good' or 'excellent', and 100 per cent responded that they would come again (data not shown). The storydriven immersive experiences 'Living in Space' and 'Survive the Swamp' were the most popular reported activities among children.

\section{Story and immersion}

The assessment of the festivals in 2017 and 2018 explored in more detail the effects of immersion in a meaningful story, and whether particular forms of immersive experience were more effective than others. Responses indicated positive attitudinal change, and post-event research in 2018 indicated positive behavioural change.

Child attendees were asked whether SMASHfestUK had any effects on their attitudes towards science or STEM subjects: 87 per cent agreed or really agreed that it

Figure 9: Indicators of Engagement, SMASHfestUK 2018 ( $n=188$ ) (Simons, 2018)

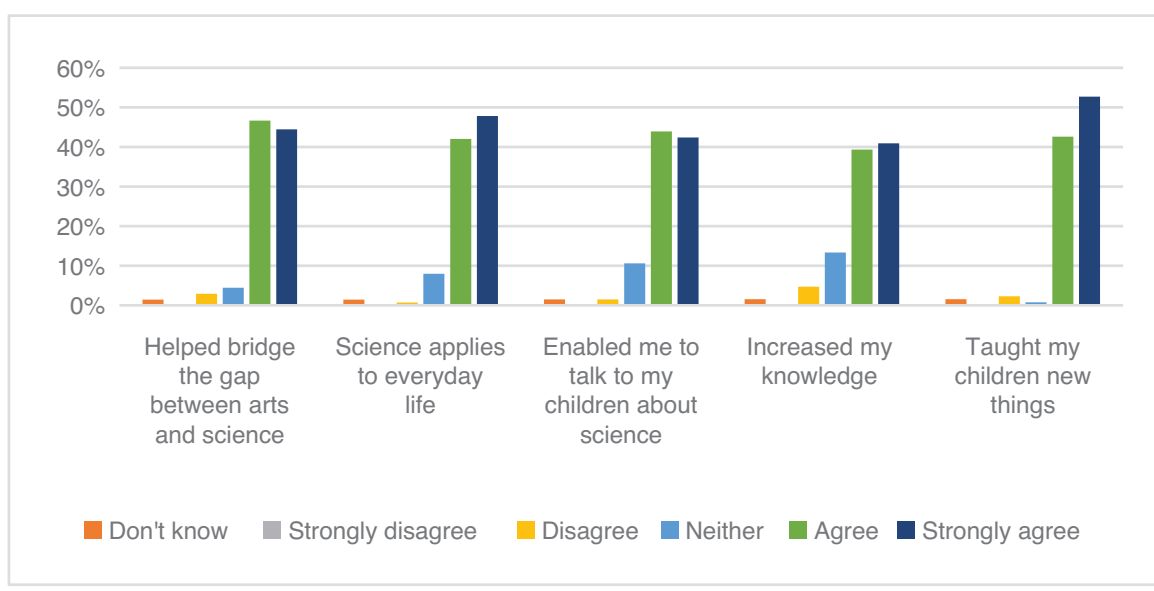


helped them understand how science connects to real life, and 83 per cent said that it had made them more excited about science; 86 per cent agreed or really agreed that it had given them a more positive attitude towards studying STEM, and 84 per cent agreed or really agreed that it would increase their confidence in science learning at school (Figure 10).

One visitor, a grandmother accompanying her grandchildren, commented:

This is an excellent display that really gets kids' minds working, it makes everyone realize that there is a creative side to the brain. The activities are helpful to the parents too, like growing plants without earth! In Deptford, there are some activities around the arts but not so much focusing on science - so this is great for us to get smart ... They really like the storyline to find out how they could survive if there was a flood - so it gets their minds working and feeds their imagination. (Simons, 2018: 32-3)

This was frequently commented on by adult visitors with daughters. One reported that the best things about SMASHfestUK was: 'The range of activities initially advertised. As a parent to a young girl, I felt it important that she is immersed in STEM-related events and activities to broaden her career related horizons'. Comments from other parents included: 'He loved the theatre because they can go in and make noise and stuff. This really puts science in an accessible context for the children.' Another parent remarked that 'it sparked many conversations amongst us ... as well as looking into qualifications and career routes.'

After the event, 50 visitors were surveyed, garnering 18 responses (36 per cent). The purpose was to explore whether parents/carers felt that there was any progressional learning from attending. All respondents provided positive accounts of their time at SMASHfestUK, using words such as 'interactive', 'amazing', 'excellent', 'fun' and 'fantastic', and 100 per cent said that they would return to another SMASHfestUK event. Further comments suggested that the activities and shows were 'inspiring' and 'educational'. The respondents also provided information about whether the learning

Figure 10: Child responses about the effect of SMASHfestUK (SF) on their attitudes $2018(n=102)$ (Simons, 2018)

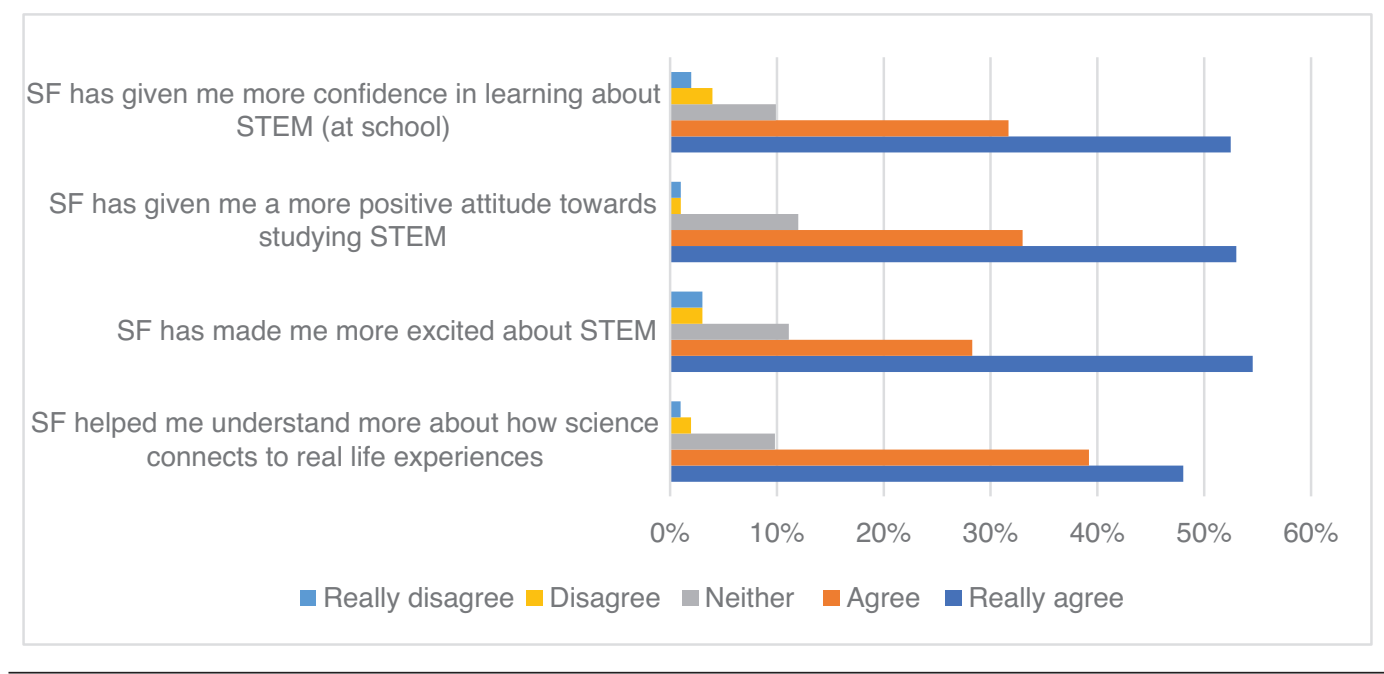


and inspiration had continued beyond the festival: 89 per cent of the respondents commented that they had continued to talk about the event, the activities and the learning that took place once they returned home. One wrote: 'Yes, the children talked about it, they have asked again about Holograms and we have created them at home as well.' Another responded:

My son wrote about it in his journal and we bring up things we heard and learned on the day in daily activities. We will refer back to Smashfest events in future activities. He continues to show others his science experiment papers so is learning by retelling it each time. (Simons, 2018: 36)

\section{Key learnings for 2020 briefing:}

1. Create a fully immersive character-led theatrical experience, in which all activities are part of the production.

2. Create an experience in which all visitors can be embodied as 'actors with agency'.

3. Embed evaluation as part of the experience storyline to gain full insight.

The success of stories and emerging narratives in the engagement of non-traditional audiences with SMASHfestUK events in Deptford 2015-18 was thought to be an exciting development in understanding how involving audiences and stakeholders in co-design processes can tailor events to communities year on year.

\section{Discussion}

The results derived from evaluations of SMASHfestUK events in Deptford 2015-18 indicate that taking a co-design approach to engagement, and tailoring an experience for specific audiences, can be highly successful in attracting new, non-traditional audiences and in retaining a supportive core audience year on year.

Employing the evidence-based establishing principles (being hyperlocal, free, entertainment-led, community based and with an overarching narrative), on which the first event was based, later allowed us to derive the inclusive engagement model, SCENE. These approaches achieved the intended goals for the attendance of local community members and positive engagement by groups identified as underserved by, and under-represented in, ISL and provided a practical conceptual model and tool for planning, generating and reviewing ISL activity.

With the early focus on accessibility and the lowering of barriers, (geographic, financial, conceptual, representational), SMASHfestUK attracted new audiences to its events. Co-design and audience feedback clarified that the overarching story, and immersion within that story, was exciting and engaging for visitors, and the number of immersive activities and level of immersion was increased across the years 2016, 2017 and 2018. Visitors remarked that the localization, not only of the physical events, but also of the stories that accompanied the events, were meaningful for them and their children. Geographical and narrative 'localization and personalization' of the stories was intended to shift attitudes in those who might have felt that 'science is not for me', to 'science is for me'.

The festival regularly attracted 70 per cent new and 'non-traditional' audiences within a total audience which rose from just over a thousand in 2015 to almost three and a half thousand in 2018. The audience was drawn largely from postcode areas neighbouring the venues in Deptford, South East London. Across the years, demographic data were collected which showed that audiences were ethnically diverse. The demographic data on 
attendance broadly reflect the demographic breakdown of Deptford, and this supports the assertion that if ISL activities are framed in the correct way, and made accessible for parents and children, there need be no lack of diversity in visitor or audience statistics. Being local and free was repeatedly reported as being important to the success of the festival in attracting new, local audiences. The overarching story, as well as branding it SMASHfestUK (that is, not as a 'science' festival), was considered important in reducing perceived barriers to engagement. Results from 2015, 2016 and 2017 showed that seeking out ISL was not a main reason for most attendees to come. This supports the 'entertainment-first' approach, while stories provided a context within which visitors were invited to imagine themselves as future scientists or engineers with agency to save the world and build their 'science identity'.

Within the cycles of reflection and co-design, an emergent effect was observed by researchers: that children engaged strongly with the stories and would develop their own personal narratives around them. We believe this may represent a form of 'narrative transportation' due to immersion within the story.

\section{Conclusion}

The SCENE model, as a method for approaching ISL planning for underserved audiences, and as a tool for tailoring those ISL experiences, has been a successful approach for development and delivery of SMASHfestUK. The approach was successful in engaging 'non-traditional' audiences who are often under-represented in ISL activity demographics. The 'prototyping' mindset was vital to ensuring that continuous improvement, experimentation and refinement were built into the development process, as was the focus on asking: 'Why, who, what, where, when and how?' for each event, every year. This produces, in SCENE, a reflective cycle and 'checklist' which could contribute to other ISL projects seeking to engage inclusively and to reach 'nontraditional' audiences.

In summary, we have shown that the SCENE model for engagement was successful in attracting non-traditional and new audiences, and that engagement with under-represented audiences can be achieved by using co-design processes to develop resonant formats and content tailored to specific audiences. Finally, we have shown that the combination of enquiry-based learning and immersing audiences in meaningful stories allows them to experience STEM agency.

Findings showed that through application of the SCENE model:

- we built new audiences

- they are audiences that do not usually come to ISL events

- they are diverse audiences

- they are girl majority audiences

- the audiences love that it is free and local

- the audiences are strongly engaged because of the stories.

Key factors in achieving this were to work in and with the communities we sought to serve, to lower known and perceived barriers to engagement, and to use tenets of storytelling which can engage visitors emotionally and intellectually, deepen their engagement and, potentially, change attitudes in real life towards adopting a more positive science identity through 'narrative transportation'.

This effect emerged through the course of SMASHfestUK work 2015-18, guided by the SCENE model (and its precursor principles). In the spirit of co-design, we would more than welcome readers applying, testing and evolving the SCENE tool and principles, and reporting back to inform its general development. 
The next step for SMASHfestUK was the testing of the SCENE model applied to a fully immersive experience (in contrast to the semi-immersive 'festival' experience), and this was done in Deptford in 2020 with the production of 'Space Plague', based on the findings of the previous 2015-18 festivals and co-design programmes. 'Space Plague' explored this emerging effect on audiences, with the assumption that positive effects on 'science identity' observed in the 2015-18 festivals would be enhanced by a fully immersive experience (Keith and Griffiths, 2020). The SCENE model informed the approach to generating and delivering 'Space Plague', and initial results suggest that the effects on science identity are indeed enhanced. A follow-up study is under way to ascertain whether the positive changes have been retained over time.

\section{Notes on the contributors}

Lindsay Keith is a BAFTA-nominated film-maker, festival producer, writer and research fellow. Following a $\mathrm{PhD}$ at Imperial College London, UK, she worked in broadcast television, founding The Refinery in 2011, and the award-winning immersive science and arts festival SMASHfestUK in 2014. She works as a research fellow at the University of Greenwich, UK, where her specialism is embodiment and behaviour change through immersive narratives.

Wyn Griffiths lectures in product design and engineering, and his research involves inclusive design, immersion and narrative transportation. He co-founded the awardwinning festival SMASHfestUK. His work spans many sectors and a disparate range of participatory design and public engagement arenas, including event, installation, experience and exhibition design, build and management.

\section{References}

Archer, L. and Moote, J. (2016) ASPIRES 2 Project Spotlight: Year 11 students' views of careers education and work experience. Accessed 27 June 2021. www.kcl.ac.uk/ecs/research/aspires/ ASPIRES-2-Project-Spotlight---Year-11-Students-Views-on-Careers-Education-and-WorkExperience.pdf

Archer, L. and Tomei, A. (2014) '"I like science but it's not for me": The need to improve STEM careers education'. School Science Review, 95 (352), 112-18. Accessed 27 June 2021. www.ase.org.uk/resources/school-science-review/issue-352/i-science-its-not-me-need-improvestem-careers-education.

Archer, L., DeWitt, J., Osborne, J.F., Dillon, J.S., Wong, B. and Willis, B. (2013) ASPIRES Report: Young people's science and career aspirations, age 10 -14. Accessed 27 June 2021. https://webcache.googleusercontent.com/search?q=cache:t0oFeOBdaKcJ:https://www.kcl.ac.uk/ ecs/research/aspires/aspires-final-report-december-2013.pdf $+\& c d=3 \& h l=e n \& c t=c l n k \& g l=u k$.

Archer, L., Dawson, E., DeWitt, J., Seakins, A. and Wong, B. (2015) "'Science capital": A conceptual, methodological, and empirical argument for extending Bourdieusian notions of capital beyond the arts'. Journal of Research in Science Teaching, 52 (7), 922-48. https://doi.org/10.1002/tea.21227.

Banfield, R., Lombardo, C.T. and Wax, T. (2015) Design Sprint: A practical guidebook for building great digital products. Sebastopol, CA: O'Reilly Media.

Bardill, A., Griffiths, W., Jones, S. and Fields, B. (2010) 'Design tribes and information spaces for creative conversations'. Paper presented at the 12th International Conference on Engineering and Product Design Education, Trondheim, 2-3 September.

Buchenau, M. and Suri, J. (2000) 'Experience prototyping'. In D. Boyarski and W.A. Kellogg (eds), Proceedings of the 3rd Conference on Designing Interactive Systems: Processes, Practices, Methods, and Techniques, DIS. New York: Association for Computing Machinery, 424-33. https://doi.org/10.1145/347642.347802.

Burns, J., Cooke, D. and Schweidler, C. (2011) A Short Guide to Community Based Participatory Action Research. Accessed 2 July 2021. https://ktpathways.ca/resources/short-guide-communitybased-participatory-action-research. 
Cable, J. and Williams, A. (2014) Community Engagement and Hyperlocal News: A practical guide. Accessed 27 June 2021. http://orca.cf.ac.uk/64903/.

Chapman, M.S. and Vivian, R. (2016) Engaging the Future of STEM: A study of international best practice for promoting the participation of young people, particularly girls, in science, technology, engineering and maths (STEM). Accessed 27 June 2021. https://cew.org.au/wpcontent/uploads/2017/03/Engaging-the-future-of-STEM.pdf.

Dahlstrom, M.F. (2014) 'Using narratives and storytelling to communicate science with nonexpert audiences'. Proceedings of the National Academy of Sciences of the United States of America, 111, 13614-20. https://doi.org/10.1073/pnas.1320645111.

Dawson, E., Seakins, A., Archer, L., Barton, A.C. and Dierking, L. (2015) Equity in Informal Science Learning. Accessed 21 June 2021. http://discovery.ucl.ac.uk/1472920/1/Dawson_Equity-brief--Youth-Equity-Pathways-in-ISL.pdf.

Deignan, T. (2009) 'Enquiry-based learning: Perspectives on practice'. Teaching in Higher Education, 14 (1), 13-28. https://doi.org/10.1080/13562510802602467.

Dewitt, J., Archer, L. and Osborne, J. (2014) 'Science-related aspirations across the primarysecondary divide: Evidence from two surveys in England'. International Journal of Science Education, 36 (10), 1609-29. https://doi.org/10.1080/09500693.2013.871659.

Flow UK (2015) Evaluation of SMASHfest 2015. Accessed 8 July 2021. https://gala.gre.ac.uk/id/ eprint/19848/.

Foth, M., Lankaster, A. and Hughes, H. (2016) 'Digital fabrication and local participation: A community maker space dissoving boundaries'. In H. Davis and J. Farmer (eds), Proceedings of the 2016 OZCHI Workshop on Digital Participation: Engaging Diverse and Marginalised Communities, 1-9.

Froonjian, J. and Garnett, J.L. (2013) 'Reaching the hard to reach: Drawing lessons from research and practice'. International Journal of Public Administration, 36, 831-9. https://doi.org/10.1080/0 1900692.2013.795161.

Gallagher, K.M. (2011) 'In search of a theoretical basis for storytelling in education research: Story as method'. International Journal of Research and Method in Education, 34 (1), 49-61. https://doi.org/10.1080/1743727X.2011.552308.

Gerrig, R. (1993) Experiencing Narrative Worlds: On the psychological activities of reading. New Haven, CT: Yale University Press.

Grand, A., Davies, G., Holliman, R. and Adams, A. (2015) 'Mapping public engagement with research in a UK University'. PLoS One, 10 (4), 1-19. https://doi.org/10.1371/journal.pone.0121874.

Green, M.C. and Brock, T.C. (2000) 'The role of transportation in the persuasiveness of public narratives'. Journal of Personality and Social Psychology, 79 (5), 701-21. https://doi.org/10.1037//00223514.79.5.701.

Griffiths, W. (2015) SMASHfestUK 2015 'Asteroid', Flickr. Accessed 26 May 2021. www.flickr.com/ photos/30542236@N04/albums/72157710821787818.

Griffiths, W., Bardill, A. and Herd, K. (2012) 'Participatory design in a compressed timeframe, through an unConference format'. Paper presented at Perspectives on Participation @ DIS 2012, Newcastle University, June.

Gutman, L.M. and Akerman, R. (2008) Determinants of Aspirations: Centre for Research on the Wider Benefits of Learning Research Report. http://eprints.ioe.ac.uk/2052/.

Harden, A., Sheridan, K., McKeown, A., Dan-Ogosi, I. and Bagnall, A.-M. (2015) Review 5: Evidence review of barriers to, and facilitators of, community engagement approaches and practices in the UK. London: Institute for Health and Human Development, University of East London. Accessed 27 June 2021. www.nice.org.uk/guidance/ng44/evidence/evidence-review-5-communityengagement-barriers-and-facilitators-pdf-2368403681.

Henriksen, D. (2014) 'Full STEAM ahead: Creativity in excellent STEM teaching practices'. STEAM, 1 (2), 1-9. https://doi.org/10.5642/steam.20140102.15.

IET (Institute of Engineering and Technology) (2008) Studying Stem: What are the barriers? Accessed 27 June 2021. https://mei.org.uk/files/pdf/Studying_Stem.pdf.

Jarvis, P.S.C. (2016) SMASHfestUK Evaluation 2016: 'Solar Storm'. Accessed 27 June 2021. https://gala.gre.ac.uk/id/eprint/19844/.

Keith, L. and Griffiths, W. (2020) "'Space Plague": An investigation into immersive theatre and narrative transportation effects in informal pandemic science education'. Journal of Science Communication, 19 (7), 1-17. https://doi.org/10.22323/2.19070801.

Land, M.H. (2013) 'Full STEAM ahead: The benefits of integrating the arts into STEM'. Procedia Computer Science, 20, 547-52. https://doi.org/10.1016/j.procs.2013.09.317.

Macdonald, A. (2014) 'Not For People Like Me?': Under-represented groups in science, technology and engineering. Accessed 27 June 2021. www.wisecampaign.org.uk/wp-content/ uploads/2018/06/not_for_people_like_me-full-report.pdf. 
MHCLG (Ministry of Housing, Communities and Local Government) (2015) 'Index of multiple deprivation 2015'. Accessed 27 June 2021. www.gov.uk/government/statistics/english-indices-ofdeprivation-2015.

MHCLG (Ministry of Housing, Communities and Local Government) (2019) 'Index of multiple deprivation 2019'. Accessed 27 June 2021. www.gov.uk/government/statistics/english-indices-ofdeprivation-2019.

Morgan, R., Kirhy, C. and Stamenkovic, A. (2016) The UK STEM Education Landscape: A report for the Lloyd's Register Foundation from the Royal Academy of Engineering Education and Skills Committee. Accessed 27 June 2021. www.raeng.org.uk/publications/reports/uk-stem-educationlandscape.

Mujtaba, T., Hoyles, C., Reiss, M., Stylianidou, F. and Riazi-Farzad, B. (2010) 'Mathematics and physics participation in the UK: Influences based on analysis of national survey results'. Paper presented at BERA Symposium, University of Warwick, 4 September. Accessed 27 June 2021. www.leeds.ac.uk/educol/documents/197832.pdf.

Mytton, J., Ingram, J., Manns, S. and Thomas, J. (2014) 'Facilitators and barriers to engagement in parenting programs: A qualitative systematic review'. Health Education and Behavior, 41 (2), 127-37. https://doi.org/10.1177/1090198113485755.

Nath, C. and Border, P. (2013) Examining Science, Technology, Engineering and Maths Education for Ages 14-19. London: The Parliamentary Office of Science and Technology.

Němec, J. and Trna, J. (2007) 'Edutainment or entertainment: Education possibilities of didactic games in science education'. In J. Němec (ed.), The Evolution of Children's Play. Brno: Masyryk University, 55-64.

Phillips, B.J. and McQuarrie, E.F. (2010) 'Narrative and persuasion in fashion advertising'. Journal of Consumer Research, 37 (3), 368-92. https://doi.org/10.1086/653087.

Rae, A. (2019) 'English Indices of Deprivation 2019: Local Authority maps'. Accessed 8 October 2020. https://imd2019.group.shef.ac.uk/.

Rossiter, M.W. (1993) 'The Matthew Matilda effect in science', Social Studies of Science, 23 (2), 325-41. https://doi.org/10.1177/030631293023002004.

Sanders, E.B.-N. and Stappers, P.J. (2008) 'Co-creation and the new landscapes of design'. CoDesign, 4 (1), 5-18. https://doi.org/10.1080/15710880701875068.

Sanders, E.B.-N. and Stappers, P.J. (2014) 'Probes, toolkits and prototypes: Three approaches to making in codesigning'. CoDesign: International Journal of CoCreation in Design and the Arts 10 (1), 5-14. https://doi.org/10.1080/15710882.2014.888183.

Sanders, E.B.-N., Brandt, E. and Binder, T. (2010) 'A framework for organizing the tools and techniques of participatory design'. In Proceedings of the 11th Biennial Participatory Design Conference, 195-8. https://doi.org/10.1145/1900441.1900476.

Schank, R.C. and Abelson, R.P. (2014) 'Knowledge and memory: The real story'. In R.S. Wyer, Jr (ed.), Knowledge and Memory: The real story (Advances in Social Cognition, Vol. 8). Hillsdale, NJ: Lawrence Erlbaum Associates 1-85.

Simons, N. (2017) SMASHFestUK 2017 Evaluation Report. Accessed 27 June 2021 http://sciencefestivals.uk/wp-content/uploads/2016/02/SMASHfestUK-2017-evaluation-report.pdf.

Simons, N. (2018) SMASHFestUK 2018 Evaluation Report: Flood!. Accessed 27 June 2021. https://gala.gre.ac.uk/id/eprint/28766/7/28766\%20SIMONS_SMASHfestUK_Festival_ FLOOD_2018.pdf.

Slater, M.D. and Rouner, D. (2002) 'Entertainment-education and elaboration likelihood: Understanding the processing of narrative persuasion'. Communication Theory, 12 (2), 173-91. https://doi.org/10.1111/j.1468-2885.2002.tb00265.x.

TISME (Targeted Initiative on Science and Mathematics Education) (2013) 'What Influences Participation in Science and Mathematics?': A briefing paper from the Targeted Initiative on Science and Mathematics Education (TISME). Accessed 27 June 2021. www.sciencecentres.org. uk/resources/academic-research/tisme-publications-including-what-influence-participationscience-and-mathematics-report/.

van Laer, T., de Ruyter, K., Visconti, L.M. and Wetzels, M. (2014) 'The extended transportationimagery model: A meta-analysis of the antecedents and consequences of consumers' narrative transportation'. Journal of Consumer Research, 40 (5), 797-817. https://doi.org/10.1086/673383.

Vorderer, P., Klimmt, C. and Ritterfeld, U. (2004) 'Enjoyment: At the heart of media entertainment', Communication Theory, 14 (4), 388-408. https://doi.org/10.1111/j.1468-2885.2004.tb00321.x.

Zamenopoulos, T. and Alexiou, K. (2018) Co-Design as Collaborative Research. Accessed 27 June 2021. https://connected-communities.org/wp-content/uploads/2018/07/Co-Design_SP.pdf. 